Original Article

\title{
PERCEIVED SERVICE QUALITY AND PATIENT SATISFACTION AT PHARMACY DEPARTMENT IN YOGYAKARTA, INDONESIA
}

\author{
MADE SRI SARASWATI ${ }^{1}$, SUSI ARI KRISTINA ${ }^{2}$, ABDUL KARIM ZULKARNAIN ${ }^{2 *}$
}

1Pharmacy Bachelor Student, Faculty of Pharmacy, Universitas Gadjah Mada, Yogyakarta, Indonesia, ${ }^{2}$ Department of Pharmaceutics, Faculty of Pharmacy, Universitas Gadjah Mada, Yogyakarta, Indonesia

Email: akarimzk08@gmail.com

Received: 14 Aug 2017 Revised and Accepted: 21 Dec 2017

\section{ABSTRACT}

Objective: To measure the gap between patients' expectations and perceptions about services delivered in the pharmacy department.

Methods: A questionnaire concerning the perceived quality of health care sent to out-patients in the pharmacy department, in a government hospital in Sleman district, Yogyakarta Province, Indonesia, during a period of 2016. Participants were two hundred patients aged 18 or older responded to the survey and provided their own ratings of the care. The SERVQUAL model was employed, consisting five main dimensions of service, are tangibles, reliability, responsiveness, assurance, and empathy. Description of respondents' characteristics, quality dimensions and patient satisfaction were examined.

Results: In our survey, $54 \%$ of patients were female and $46 \%$ male. Thirty-one percent of patients were 45-54 y old. Using servqual model we found a gap-0.487 with service quality mean score 2.938; (SD 1.16) and patient satisfaction mean score 3.425 (SD 0.54). Patients with less education were more satisfied than those with more education. Gaps existed between all five expectation categories and 'overall perception' of quality. The direction of the gaps indicated higher perceived quality than expected (all statistically significant) with responsiveness domain demonstrating the largest unfavourable gaps.

Conclusion: We found the SERVQUAL model to be useful in revealing differences between patients' preferences and their actual experience in health care service quality.

Keywords: Service quality, Patient's satisfaction, Servqual, Pharmacy department

(C) 2018 The Authors. Published by Innovare Academic Sciences Pvt Ltd. This is an open access article under the CC BY license (http://creativecommons.org/licenses/by/4.0/) DOI: http://dx.doi.org/10.22159/ijpps.2018v10i2.22018

\section{INTRODUCTION}

Satisfaction defined as a person's feelings of happiness or displeasure as a result of comparing a product/service's outcome in relation to their expectations [1]. If it happens that the expected performance exceeds perceived performance then, customers become dissatisfied. On the other hand, if the expectation is more than perceived performance, customers turn to be satisfied.

Many studies reported that patient's satisfaction is influenced by a number of factors [2,3] and according to Peprah et al., (2014), the following factors play a critical role in the satisfaction of patients; the attitudes of health practitioner toward patients, the capacity to deliver prompt service without wasting time, ability to disseminate information to patients and the availability of up-to-date equipment [4]. Parasuraman et al., (1985) explained satisfaction in relation to service quality. They argued that service quality is defined as the gap between predicted or expected service (customer expectations) and perceived service (customer perceptions) [5]. If customers' expectation is greater than performance, then perceived quality is regarded less than satisfactory and a service quality gap arises. This in effect does not necessarily mean that the service is of low quality but rather customer expectations have not been met and therefore customer dissatisfaction occurs and this present opportunity for improving service to meet customer [6].

The Servqual model is a tool used for measuring service quality and consequently the satisfaction of clients [5]. It begins with the assumption that service quality is a function of customer's expectation of a service and their perceptions of the service actually rendered. To ascertain satisfaction, the difference between these variables (customers' expectations and perceived service actually delivered) is determined. Tucker et al. (2001) asserts that Servqual is a reliable instrument for determining service quality and satisfaction of customers and have been applied in different studies in different service settings [7].
There are a number of critical issues relating to healthcare services that highlight the need to assess and measure patients' satisfactions and improve them $[8,9]$. Prakash $(2010)$ puts forward that health which is particularly the relief or cure of ill health, is universally necessary and creates the needed attention to provide high-quality services in response to development in medicine [10].

As a result, assessing and measuring patient's satisfaction and perceived service quality is an important issue for a healthcare provider to understand what is cherished by patients, and to know where, when and how service can be altered or possible improvement can be made as well as how the scarce resources of the healthcare service would be distributed. Therefore, the objective of this study was to assess patient's satisfaction using SERVQUAL model, consisted of five dimensions, and identify the gap between patient expectation and patient perception of pharmacy service quality.

\section{MATERIALS AND METHODS}

\section{Methods}

\section{Study design and population}

This research was a cross-sectional survey study. The study population was the patients who had visited the General Hospital of Sleman District, Yogyakarta Province. Respondents for the study were selected by using convenience sampling technique [11]. The SERVQUAL instrument by Parasuraman et al., (1985) was adapted and modified to capture the relevant data [5]. The questionnaire was pre-tested, refined and finally administered to the target sample through personal contact by the researcher. Informed Consent information was attached to each questionnaire. A total of two hundred and forty-five structured questionnaires were continuously administered. From this number, only two hundred were valid and eligible for analysis. This produced response rate as $82 \%$. 


\section{Servqual questionnaire}

To identify patients' needs and expectations, both perceptions and expectations of service were measured. The SERVQUAL instrument, in its original form, contains twenty-two pairs of Likert scale statements structured around five service quality dimensions as the followings: (i) Tangible, describes the appearance of physical facilities, personnel and equipment; (ii) Reliability, deals with the ability to perform the promised service dependably and accurately; (iii) Responsiveness, considers the willingness to help customers and provide prompt service. (iv) Assurance talks about the knowledge and courtesy of employees and their ability to inspire trust and confidence, and; (v) Empathy: the ability to provide caring and individualized attention to customers.

The twenty-eight pairs of statements are designed to fit into the five dimensions of service quality. The scale for measuring was made up of a four-point scale starting from "strongly agree" (4) to "strongly disagree" (1) accompanies each statement. The "strongly agree" end of the scale is designed to correlate with high expectations and high perceptions (Parasuraman et al., 1985, 1988. The gap score for each statement is computed as the perception score minus the expectation score. The presence of a positive gap score means that expectations have been met or exceeded and a negative score also implies that expectations are not being met. Gap scores for each individual statement can be analysed and aggregated to give an overall gap score for each dimension.

\section{Data analysis}

The data were analysed using SPSS (version 16.0) for descriptive statistics. The gap score which indicates patients' satisfaction was determined by the service quality gap model. According to this model, the service quality is a function of perception and expectations and can be modeled as:

$$
S Q=\sum_{i=1}^{k}\left(P_{i j}-E_{i j}\right)
$$

Where:

$\mathrm{SQ}=$ overall service quality; $\mathrm{k}$ number of attributes.

$\mathrm{Pij}=$ Performance perception of stimulus i with respect to attribute $\mathrm{j}$.

Eij $=$ Service quality expectation for attribute $\mathrm{j}$ that is the relevant norm for stimulus i.

\section{RESULTS AND DISCUSSION}

Table 1 shows detailed information on demographic data and background characteristics of respondents.

Table 1: Sociodemographic characteristics of respondents

\begin{tabular}{|c|c|c|}
\hline Characteristics & $\mathbf{N}$ & $\%$ \\
\hline \multicolumn{3}{|l|}{ Gender } \\
\hline Male & 104 & 52 \\
\hline Female & 96 & 48 \\
\hline \multicolumn{3}{|l|}{ Age } \\
\hline$<21$ & 8 & 4 \\
\hline $21-30$ & 40 & 20 \\
\hline $31-40$ & 36 & 18 \\
\hline $41-50$ & 68 & 34 \\
\hline$>50$ & 68 & 34 \\
\hline \multicolumn{3}{|l|}{ Educational level } \\
\hline None & 10 & 5 \\
\hline Less than secondary & 32 & 16 \\
\hline Secondary and up & 158 & 79 \\
\hline \multicolumn{3}{|c|}{ Monthly income (million IDR) } \\
\hline$<1$ & 22 & 11 \\
\hline $1-2$ & 52 & 26 \\
\hline $2,1-3$ & 66 & 33 \\
\hline$>3$ & 44 & 22 \\
\hline \multicolumn{3}{|c|}{ Health insurance coverage } \\
\hline Yes & 96 & 48 \\
\hline No & 104 & 52 \\
\hline \multicolumn{3}{|c|}{ Frequency of visit (within six months) } \\
\hline$<3$ & 42 & 21 \\
\hline $3-10$ & 58 & 29 \\
\hline$>10$ & 100 & 50 \\
\hline
\end{tabular}

The respondents' age as depicted in table 1 indicated that the age range varied 18-30 (24\%), 31-40 (18\%), 41-50 (34\%), and>50 y (34\%). Fivty five percent of the respondents were males whilst the remaining 48 percent were females. In total, $79 \%$ of the respondents had formal education ranging from secondary to tertiary while about $16 \%$ only received primary education and $5 \%$ did not have formal education. All these could have very important implications for how respondents perceived satisfaction of the service delivery.

Table 2: Service quality dimension gap score

\begin{tabular}{|c|c|c|c|c|}
\hline \multirow[t]{2}{*}{ S. No. } & \multirow{2}{*}{ Service quality dimension } & Perception & Expectation & Gap score \\
\hline & & Mean score & \multicolumn{2}{|l|}{ Mean score } \\
\hline 1 & Reliability & 3.05 & 3.49 & 0.44 \\
\hline 2 & Responsiveness & 2.87 & 3.46 & 0.59 \\
\hline 3 & Assurance & 2.90 & 3.37 & 0.47 \\
\hline 4 & Emphaty & 2.94 & 3.43 & 0.49 \\
\hline 5 & Tangibles & 2.94 & 3.39 & 0.45 \\
\hline
\end{tabular}

The service quality dimension gap score (table 2) which is the discrepancy between patient's expectation and perception about the dimensions of service quality revealed that negative gaps occurred in all of the dimensions employed in the study. The dimensions with the highest negative gaps were Responsiveness (-0.59), followed by Emphaty $(-0.49)$ and Assurance $(-0.47)$. The negative gap of all 
dimensions means that patients were dissatisfied with the service quality. This suggests that there is more room for the hospital to improve service quality [12] in relation to the dimension of Responsiveness, Emphaty, and Assurance. Further, SERVQUAL allows for prioritisation across the five dimensions by assessing gap score of each dimension. Across the five dimensions, statistically significant gap scores were found for Responsiveness Emphaty, and Assurance. Comparison of these gap scores suggests that the priority gap as far as patients' assessment of service quality is concerned is that of Responsiveness since it has the largest gap score. Ramsoek $e t$ al. used the same approach to prioritise where improvements to service quality can best be achieved [13], concluding that Responsiveness is the priority dimension given that it had the largest negative gap score. Clearly, within the Responsiveness dimension, there are different aspects of performance as denoted by the individual statements. It may be possible to prioritise further between these aspects of service quality by examining the gap scores for each. Other things being equal, priority can be given to statements that show higher gap.

This suggests that management should consider ways of rendering prompt and timely service to patients $[14,15]$.

Among five sociodemographics, only education level was associated with the patient satisfaction level. It indicated that patients were able to expect the quality of services when they have higher education compare with the lower one (table 3).

Table 3: Relationship between sociodemographic characteristics and satisfaction in pharmacy services

\begin{tabular}{|c|c|c|c|c|c|}
\hline \multirow[t]{2}{*}{ Characteristics } & \multicolumn{2}{|c|}{ Satisfaction level } & \multirow[t]{2}{*}{$\mathbf{N}$} & \multirow[t]{2}{*}{$\mathrm{X}^{2}$} & \multirow[t]{2}{*}{ p-value } \\
\hline & Satisfy, N (\%) & Not satisfy, $\mathbf{N}(\%)$ & & & \\
\hline Gender & & & & 0,013 & 0,911 \\
\hline Male & $16(25)$ & $88(75)$ & 104 & & \\
\hline Female & $14(15)$ & $82(85)$ & 96 & & \\
\hline Age & & & & 0,473 & 0,976 \\
\hline$<21$ & $2(25)$ & $6(75)$ & 8 & & \\
\hline $21-30$ & $6(15)$ & $34(85)$ & 40 & & \\
\hline $31-40$ & $6(17)$ & $30(83)$ & 36 & & \\
\hline $41-50$ & $6(9)$ & $42(62)$ & 68 & & \\
\hline$>50$ & $10(15)$ & $58(85)$ & 68 & & \\
\hline Educational level & & & & 11,853 & $0,037^{*}$ \\
\hline None & $6(60)$ & $4(40)$ & 10 & & \\
\hline Less than secondary & $2(6)$ & $30(94)$ & 32 & & \\
\hline Secondary and up & $22(14)$ & $136(86)$ & 158 & & \\
\hline Monthly income (million IDR) & & & & 5,716 & 0.335 \\
\hline$<1$ & $10(45)$ & $12(55)$ & 22 & & \\
\hline $1-2$ & $25(48)$ & $37(71)$ & 52 & & \\
\hline $2,1-3$ & $26(39)$ & $40(61)$ & 66 & & \\
\hline$>3$ & $10(23)$ & $34(77)$ & 44 & & \\
\hline Health insurance coverage & & & & 1,073 & 0,585 \\
\hline Yes & $16(17)$ & $80(83)$ & 96 & & \\
\hline No & $14(13)$ & 90 (87) & 104 & & \\
\hline Frequency of visit (within six months) & & & & 1,269 & 0,530 \\
\hline$<3$ & $4(10)$ & $38(90)$ & 42 & & \\
\hline $3-10$ & $12(21)$ & $46(79)$ & 58 & & \\
\hline$>10$ & $14(14)$ & $86(86)$ & 100 & & \\
\hline
\end{tabular}

This study had several limitations. Firstly, the respondents were made up of only outpatients thus views of inpatients could not be captured during the studies which in effect may affect the result to some extend, therefore, a future study could consider including inpatients. The study was also limited to patients of a public hospital only. As a result, it is therefore suggested that further study be carried out in the private healthcare centres in order to ascertain a comprehensive understanding of patients' satisfaction in healthcare delivery. To fully assess the quality of healthcare delivery and patients satisfaction, it is expected that both technical and functional aspects of the service be considered. As another limitation to this study, it considered only the functional aspects of the service delivery thus only patients' view was used for the research.

\section{CONCLUSION}

The understanding and measurement of service quality and patients' satisfaction as seen by the patient is equally important to health care delivery because it is a concept integral to the provision of a better, more focused quality service for patients. In order to achieve this, it is clearly necessary to capture information on patient needs, expectations and perceptions so as to assess their satisfaction about the service they receive. This will then help health professionals identify where service improvements are needed.

\section{ACKNOWLEDGEMENT}

We thank all participants who participated in this survey and the Head of Pharmacy Department of Sleman District Hospital who helped in the collection of data.

\section{AUTHORS CONTRIBUTIONS}

Data collection process was performed by Made Sri Saraswati, while Susi Ari Kristina conducting a review on questionnaire and data analysis. Abdul Karim Zulkarnain contributed on the design of the questionnaire, supervising data analysis process and writing manuscript.

\section{COMPETING INTERESTS}

The author (s) declare that they have no competing interests.

\section{REFERENCES}

1. Kotler P. Marketing Management. edition F. editor: Pearson Education, Inc; 2003.

2. Lim PC, Tang NKH. A study of patients' expectations and satisfaction in singapore hospitals. Int J Health Qual Assoc 2000;13:3.

3. Wisniewski W. Measuring service quality in a hospital colposcopy clinic. Int J Health Qual Assoc 2005;18:217-28.

4. Peprah AA. Determinant of Patients' Satisfaction at Sunyani regional Hospital, Ghana. Int J Buss Soc Res 2014;4:96-108.

5. Parasuraman A, Zeithaml VA, Berry LL. SERVQUAL: a multiitem scale for measuring consumer perceptions of the service quality. J Retailing 1888;64:12.

6. Satibi S. National health coverage system: Pharmacists and JKN participant satisfaction in primary health facilities. Indonesian J Pharm 2016;27:232-40.

7. Tucker JL, Adams SR. Incorporating patients' assessments of satisfaction and quality: an integrative model of patients' evaluations of their care. Man Serv Qual 2001;11:272-87. 
8. Anderson EA, Zwelling LA. Strategic service quality management for health care. Am J Med Qual 1996;11:3-10.

9. Mahmudah RL, Ikawati Z, Wahyono D. A qualitative study of perspective, expectations, and needs of education in chronic obstructive pulmonary disease (COPD). Int J Pharm Chem Res 2017;9:32-5

10. Prakash B. Patient satisfaction. J Cutan Aesthet Surg 2010;3:151-5.

11. Saunders M, Lewis $P$, Thornhill A. Research Methods for Business Students. London; 2009.

12. Adepu R, Patel H, Sapthagiri R, Gurumurthy P. Drug and therapeutic information service provided by clinical pharmacists for an improved patient care: an experience from a tertiary care teaching hospital. Asian J Pharm Clin Res 2015;8:175-8.

13. Ramseook-Munhurrun P, Lukea-Bhiwajee SD, Naidoo P. Service quality in the public service. Int J Man Mark Res 2010;3;33-50.

14. Dabestani R, Shahin A, Shirouyehzad H, Saljoughian M. A comparative study of ordinary and fastidious customers' priorities in service quality dimensions. Tot Qual Man Buss Excell. 2017;28.https://doi.org/10.1080/14783363.2015. 1082420 .

15. Khekale SN, Askhedkar R, Parikh RH, Gosavi DD. Role of time study in the emergency department of an indian hospital for quality health care. Asian J Pharm Clin Res 2017;10:55-8. 